\title{
WHAT MIGHT THE PANDEMIC HAVE DONE TO AND FOR HIGHER EDUCATION?
}

\author{
Paul Gibbs, East European University, Georgia
}

\begin{abstract}
What is the educational response to Covid 19 doing to our humanity? The paper considers the disruption to the diversity of teaching approaches and the dominance of on-line teaching in universities. It asks the question, with the intent of discussion, "Are we really aware of how the dominance of online learning is affecting our humanity?"
\end{abstract}

Keywords: Technological way of being, Covid19, Heidegger, individual identity

At the outset I want to state that I do believe that Covid is a serious health, social, economic and moral problem. Covid 19 exists and can bring huge sorrow and suffering. It is real and it is discriminatory. It finds the injustices in our society of poverty and ethnicity and exploits them in its own destructive ways. The palliative of a vaccine will disguise the underlying reason for this and possibly all pandemics but the solution is change; massive change in our societies to liberate people to be themselves, to be individuals and remove the shackles of being the same. This is an educative problem both within and external to our institutions of education. For many, the Covid 19 pandemic has brought heroic moments of kindness, of empathy and of caring, countered by untruths, power grabbing, insensitivity and bad faith. Certainly, instances of the bad are becoming more prevalent as the impact of the more compassionate acts fades into familiarity. What the pandemic has done, I believe, is to highlight for many the need for companionship, friendship and love in a very personal way and often in ways that transcend the ability of our technological age to satisfy.

Those ideas retained, for the most part, anthropogenic notions of reality and sought to harness technology as a tool in the hegemony of humanity rather than, as Epstein (2012) suggests, a transformation in humanity where our being became that predicted, although not ridiculed, by Heidegger (1977) as a technological way of being. The new epoch is not post- anything but rather a transformative otherness which transforms notions of self, nature and culture. It goes beyond the reshuffling of post-humanism to a reinterpretation 
Gibbs, $P$.

What Might the Pandemic Have Done to and for Higher Education?

of humanity itself. It is imaginative transmutation of postmodernism and the hidden continuity of privilege that underlies its conceptual roots.

It is with Derrida's (2001) comments and the more recent paper of Mui and Murphy (2020) in mind that I wish to question Covid 19's influences on the rapid adoption of online teaching, virtual learning platforms, "smart content" creation, AI-driven chat robots and deep learning, on the higher education which has produced profound and disruptive effects of the digital transformation of knowledge. For sure it has placed, to use Derrida's phrase, the technician academic at the centre of knowledge dissemination. Certainly, forms of technology which are harnessed to help humanity flourish are valuable and, in that, the development of vaccines can be one technology-driven activity worthy of note. However, exploitation by the privileged is simply exaggerated if vaccines are not provided patent-free and nations buy up supplies just because they might need them, leaving others needing therapy or immunisation wanting because of their greed and the self-interest of others: white middle classes to the lifeboats first?

Being locked away from the outside world feeds images of close friends and family through an electronic representation of them, prevented from testing their existence other than through the collection of pixels that configure a reality we have come to accept as real and feed images of a world variously winning, defeating and surrendering to the enemy of Covid 19. We are encouraged to go about our lives in these technological cocoons, losing familiarity with other ways of being, captured in a Heideggerian cave, waiting, not to be liberated but to accept the new normal. Encouraged by the ascetic of the present through the lens of political self-interest, leaves us entrapped in the same delimiting environment, to be motivated to practise restraint by how difficult it is for those who make decisions to keep us in such servitude yet who are exempt because of the pain they bear for us. When we are in need to gather, to break out from our technological, enforced isolation, we are chastened and sent deeper in the cave to learn the lessons of conformity.

If this is not sufficient, we are subjected to the "the games", where those forced into service of gladiatorial harmony fight for our pleasure on the battlefield of team sports, or we are fed past recordings, both fictional and "real", of the way we were. These nostalgic episodes provide us with the reassurances of our own heroic behaviour in confronting the past and moving forward into the new normal where companionship and humanity are refined to make us always dependent on the owners of the technology which defines our new normal. Reward comes from returning to the real world of work only to be subjected to deep quarantine if the rules of parole are broken. Guilt is layered on familial, local, national and international images of those whose woe is created by people just like us who carelessly and selfishly put our interests above the collective. Releasement comes with physical distancing, face masks to hide our emotions and a focus on work to ensure we can sustain 
Gibbs, $P$.

What Might the Pandemic Have Done to and for Higher Education?

the new order. We are like contestants in game shows where the judges have nothing to lose compared to us but who expect reassurance and sympathy for their risk-free decisions.

Heidegger (1962) describes this temporal notion of time as not our ordinary understanding of time. This time levels off and covers up the temporality and shows itself as a sequence of "nows" which are constantly "present-at-hand", in contrast to the readiness-to-hand of equipment, which are simultaneously passing away and coming along. Time is understood as a succession, as a "flowing stream" of "nows", and as the course of time (p.474). Such a temporalisation is encouraged by the provision on open access on-line learning, accessible to be consumed whenever it suits the need of consumption. This fetish of consumption is spreading more rapidly than the pandemic, encouraging education to be used not realised: to be packaged not experienced and to be defined by effectiveness metrics of use rather than changes in the being of the learner. Simpson's (1995) temporalisation of knowledge is helpful to draw more distinctly the separation I wish to highlight. She argues that: "the technological project's focus is on securing an end, its attitude towards temporality is that time, in its unruliness, must be domesticated, must be brought under control. Opposed to this, praxis fully recognises time as its field of action and as an enabling medium - for instance, the meaningful action of praxis as an application or repetition of the past understood as an historical legacy - and seeks, ideally, to maintain the singleness of individual identity through the vicissitudes of temporal existence." (Simpson, 1995; p.57).

So what might be a solution to the totalising of convenience education, facilitated by technology and transformed for mass consumption by the onset of the humanity degenerative impact of the pandemic? One response might be to reclaim our individuality and agency. Freedom resides in our choice to act on our potential, and potentialities are aligned with the properties of the haeccetias (the thingness of a thing) that determines its powers to act. Thus, not all the properties of a thing are equally important to the understanding of the specific activities, relationships, commitments, etc. which give meaning to an individual's identity but all contribute to our potentialities to realise our potentiality to be. The exploration of our being provides the potential for us to understand our life project and to seek it; to understand being as our becoming. It is not deterministic, but neither is it unencumbered; it requires a blending of knowledges and realities in order that we might have the power to reflect and deliberate about the impact to be achieved by our actions. Our individuality is the freedom with which we make choices as to our becoming in the flux of this unity, and education might function to offer a lens on the dignity of humanity. We need to take a stance on ourselves and it is our individual historicality and our future possibilities that need to be disclosed so that we might truthfully take this stand on ourselves, and our formal education, among its other functions, should facilitate this. It will require a stringency and resoluteness in educational 
Gibbs, $P$.

What Might the Pandemic Have Done to and for Higher Education?

institutions' activities which will reveal the importance to our being. This needs disclosure of a way of being in the present besides the generalised way of being of others which, I perceive, is current in ideas such as performativity. If education institutions do not take up the challenge, but dwell in the tranquillity of external directives, always ready-to-hand to shape a future, they will fail their communities and embrace the type of instrumentalism advocated by those who would wish to control and manipulate. Such an education is susceptible to turning scholars into workers whose choice of possibilities is crafted by others in the spirit of machination.

A way of realising the potential that resides within us to do this, as a capability to become, is to perceive the potential for action in the form of the realities of the transcendentals. In more detail, achievement requires activities full of political, social and economic power, and we make our being feasible (a) by questioning the reality of our everyday experience in the knowledge we have of ourselves and (b) with a preparedness and courage to create new knowledge of ourselves from the engagement.

How might we cultivate our will through beauty, unity and truth in all we do in our everyday lives and how might we attune to this in our being? Such attunement is required, for the media all too often presents the ugly and vile, not the beautiful, the good and the true and we might thus lose our capability to reflect in situ on the negative potential of our willed actualisation rather than the good that is present and unrealised. By making the effects of the balance of particularities and singularities conspicuous in the different ways that they are comprehended through discussing and sharing meaning, the mystery and wonder of experiencing beauty, unity and truth can be contextualised in all discourses.

Our individuality is the freedom with which we make choices as to our becoming in the flux of this unity and education might function to offer a lens on the dignity of humanity. This requires a reversal of the concentration of power in government and its agencies, which is exercised more easily on a homogeneous mass than when engaging with freethinking individuals. Such a position has obvious pedagogical interventions, especially where students self-develop as a central to, rather than by-product, of education. It structures curriculum to be of both political and moral relevance to a world in which the students exist as individuals and it develops self-agency. There are difficulties in trying to integrate freedom and moral self-cultivation and the use of ready-made lists of values to be internalised by students is clearly inappropriate, for they carry the colonising tendencies of the dominant power and thus value system.

Clearly, education at all levels cannot, on its own, change the world, but it can advocate notions of transformation and, especially, embrace a notion of transdiscplinarity with the cultivation of teaching and researching as phronesis, phantasia, and parrhesia that resists 
a simplistic rendering of a critical and technological understanding of being but allows us, as advocated by Heidegger, to learn how to think anew. Through insight in the present the lamination of realities as we know them will seem as nothing as we become able to live in non-human ecologies. To cope, we need to develop transdisciplinary pedagogy as a patterning of thinking in and beyond complexity. The more we use our imaginations to widen the limits of our world and, in so doing, the more thinking will become poetic and thus prophetic. New knowledges can be formed and can merge under epistemologies of meaning and, if the technologically- enhanced potential of our being is awoken, the next epoch will be post-nothing.

This paper has attempted to raise an argument for us to work harder to imagine and find ways which respect the ecology of humanity and not reshape it through our attempts to provide education. It is not to deny the benefits of technology but to ensure it is harnessed for educative purposes to enable humanity's flourishing, not to facilitate the decline in the value of education through opportunistic use of economically-devised methods of knowledge dissemination. It is to open or perpetuate a discussion on how we shape our future as technology (intentionally or not) destroys our environment but physically, intellectually and emotionally and what we might do to prevent that.

\section{References}

Derrida, J. (2001). The future of the profession or the university without condition. In T. Cohen (Ed.), Jacques Derrida and the humanities: A critical reader. Cambridge: Cambridge University Press.

Epstein, M. (2012). The Transformative Humanities. New York: Bloomsbury.

Heidegger, M. (1962). Being and Time. Oxford: Blackwell.

Heidegger, M. (1977). The Question Concerning Technology (W. Lovitt, trans.). New York: Harper Torchbook.

Mui, C. L., \& Murphy, J. S. (2020). The University of the Future: Stiegler after Derrida. Educational Philosophy and Theory, 52(4), 455-465.

Simpson, L. C. (1995). Technology, Time and the Conversation of Modernity. New York, NY and London: Routledge. 